\title{
Heparin Mimetic Peptide Nanofibers Promote Angiogenesis
}

\author{
Rashad Mammadov, ${ }^{\dagger}$ Busra Mammadov, ${ }^{\dagger}$ Sila Toksoz, ${ }^{\dagger}$ Bahri Aydin, ${ }^{\dagger}$ Ramazan Yagci, ${ }^{\S}$ Ayse B. Tekinay, ${ }^{*}$, \\ and Mustafa O. Guler ${ }^{*,+}$
}

${ }^{\dagger}$ UNAM-Institute of Materials Science and Nanotechnology, Bilkent University, Ankara 06800, Turkey
${ }^{\ddagger}$ Department of Ophthalmology, Medical School, Mersin University, Mersin 33343, Turkey
${ }^{\$}$ Department of Ophthalmology, Medical School, Fatih University, Ankara 06510, Turkey

Supporting Information

ABSTRACT: New blood vessel formation (angiogenesis) is one of the most important processes required for functional tissue formation. Induction of angiogenesis is usually triggered by growth factors released by cells. Glycosaminoglycans (e.g., heparan sulphates) in the extracellular matrix aid in proper functioning of these growth factors. Therefore, exogeneous heparin or growth factors were required for promoting angiogenesis in previous regenerative medicine studies. Here we report for the first time induction of angiogenesis by a synthetic nanofibrous peptide scaffold without the addition of any exogenous growth factors or heparin. We designed and synthesized a self-assembling peptide amphiphile molecule that is functionalized with biologically active groups to mimic heparin. Like heparin, this molecule has the ability to interact with growth factors and effectively enhance their bioactivity. The nanofibers formed by these molecules were shown to form a 3D network mimicking the structural proteins in the extracellular matrix. Because of heparin mimicking capabilities of the peptide nanofibers, angiogen-

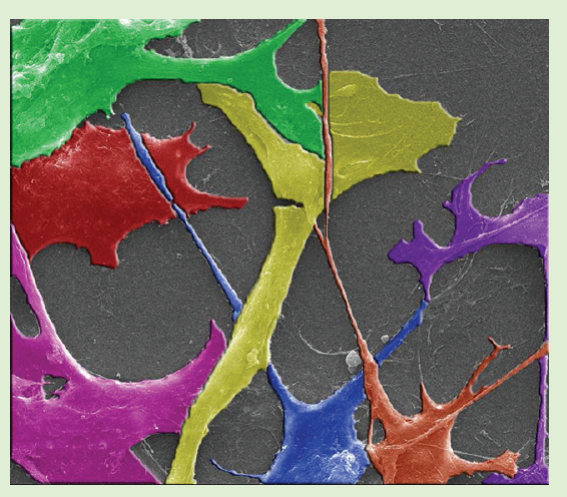
esis was induced without the addition of exogenous growth factors in vitro. Bioactive interactions between the nanofibers and the growth factors enabled robust vascularization in vivo as well. Heparin mimetic peptide nanofibers presented here provide new opportunities for angiogenesis and tissue regeneration by avoiding the use of heparin and exogenous growth factors. The synthetic peptide nanofiber scaffolds enriched with proper chemical functional groups shown in this study can be used to induce various desired physiological responses for tissue regeneration.

\section{INTRODUCTION}

Regenerative medicine studies offer promising therapeutic approaches for the repair of damaged tissues. Induction of angiogenesis (new vessel formation) is an important mechanism for tissue repair. ${ }^{1}$ The capillaries can only deliver oxygen and nutrients to the cells that are located at a distance of up to $200 \mu \mathrm{m}$, and thus angiogenesis is required for cells further away during new tissue formation. ${ }^{2}$ Angiogenesis is triggered by the detection of neovascularization signals by endothelial cells, which in turn differentiate to form new capillaries. Structural proteins of the extracellular matrix (ECM) (laminin, collagen, etc.), growth factors (VEGF, FGF-2, etc.), and glycosaminoglycans (heparan sulfate, etc.) make up a framework for detection of neovascularization signals by endothelial cells. Understanding the interactions between these biomolecules during angiogenesis and their roles in the regulation of angiogenic processes paves the way to design synthetic biomaterials that can mimic the bioactivity of natural materials.

Conventional tissue engineering strategies utilized some of the biological molecules mentioned above to provide bioactivity for promoting angiogenesis ${ }^{3}$ because synthetic biomolecules that have been produced so far lacked the ability to mimic the functions of all of these biological components. The main motivation for developing new synthetic ECM mimicking biomaterials is to minimize utilization of the above-mentioned natural biomacromolecules exogenously with the aim of reducing cost, preventing batch-to-batch variation, and avoiding biological contamination. Therefore, designing smart biomaterials that can manipulate endogenous factors for desired bioactivity is essential. Recent research efforts have focused on developing new scaffold materials with proper functional groups that are sufficient to induce the desired physiological response in vitro without any need for growth factors or any other supplements. ${ }^{4}$

Among the basic components of the framework that aids in the detection of neovascularization signals by endothelial cells, heparan-sulfate proteoglycans (HSPGs) bind to angiogenesispromoting growth factors and their receptors through heparan sulfate chains and regulate growth factor signaling. ${ }^{5-8}$ Mice lacking heparan sulfate chain on HSPG molecule reveal defective angiogenesis and wound healing. ${ }^{9}$ Binding of growth factors to HSPGs, which strictly depends on the distribution of functional groups, such as sulfate, hydroxyl and carboxyl groups, on heparan sulfate chains, protects growth factors from degradation, increases local concentration of growth factors, and enhances

Received: May 16, 2011

Revised: August 15, 2011

Published: August 19, 2011 
growth factor-receptor interactions, which are important for long-term stimulation of signaling pathways in endothelial cells. ${ }^{8,10-12}$ Using glycosaminoglycans (e.g., heparin) within tissue engineering scaffolds has been shown to enhance angiogenesis significantly while reducing the need for exogenous growth factors in in vivo studies. ${ }^{13,14}$ However, being an animal-derived product, utilization of heparin in tissue engineering systems might have potential side effects (e.g., immune reactions). ${ }^{15}$ Designing heparin mimetic biomaterials will have high impacts in cellular therapy and regenerative medicine because they will enable us to avoid the use of heparin while minimizing the use of exogenous growth factors.

Peptide-based scaffolds are promising candidates for designing smart biomaterials because they are suitable for attachment of various bioactive chemical groups along with their biocompatibility. A peptide amphiphile (PA) scaffold for angiogenesis was previously developed by mixing heparin-binding PA molecule and heparin. ${ }^{13}$ Heparin-binding PA molecule allowed growth factor binding and helped the formation of various functional tissues. ${ }^{13,16,17}$ The addition of functional groups inspired by heparin on peptide sequences and polymers has also been previously shown to enhance growth factor binding capacity. ${ }^{18-22}$ For example, sulfated alginate polymers gained growth factor binding capability and induced in vivo angiogenesis significantly better than nonsulfated alginate in the presence of growth factors. ${ }^{19,23}$

In this study, we designed and synthesized a heparin-mimetic PA molecule functionalized with bioactive groups for mimicking heparin activities. The heparin-mimetic PA molecules self-assemble to form nanofibers with abilities to bind to growth factors and to promote angiogenesis without the need for the addition of exogenous heparin or growth factors. This work demonstrates that nanostructures with bioactive chemical groups inspired by biological macromolecules can be used to activate biological machinery for regenerative medicine applications. ${ }^{4,24}$

\section{EXPERIMENTAL SECTION}

Materials. 9-Fluorenylmethoxycarbonyl (Fmoc) and tert-butoxycarbonyl (Boc) protected amino acids, [4-[ $\alpha-\left(2^{\prime}, 4^{\prime}\right.$-dimethoxyphenyl) Fmoc-aminomethyl]phenoxy] acetamidonorleucyl-MBHA resin (Rink amide MBHA resin), Fmoc-Asp(OtBu)-Wang resin, and 2-(1H-Benzotriazol-1-yl)-1,1,3,3-tetramethyluronium hexafluorophosphate (HBTU) were purchased from NovaBiochem and ABCR. Heparin was purchased from Sigma-Aldrich. The other chemicals were purchased from Fisher, Merck, Alfa Aesar, or Aldrich. All chemicals were used as provided. VEGF (vascular endothelial growth factor) used in angiogenesis assays were purchased from Sigma-Aldrich (mouse) and Invitrogen (human). Both mouse and human bFGFs (fibroblast growth factor) (FGF-2) were purchased from e-Biosciences.

Synthesis of Peptide Amphiphiles. PAs were constructed on Rink Amide MBHA resin or Fmoc-Asp(OtBu)-Wang resin. Amino acid couplings were performed with 2 equiv of Fmoc-protected amino acid, 1.95 equiv of HBTU, and 3 equiv of $N, N$-diisopropylethylamine (DIEA) for $2 \mathrm{~h}$. Fmoc removal was performed with $20 \%$ piperidine/dimethylformamide solution (DMF) for $20 \mathrm{~min}$. We used 10\% acetic anhydride solution in DMF to block remaining free amine groups after amino acid coupling. After each step, resin was washed by using three times DMF, three times DCM, and three times DMF, respectively. Sulfobenzoic acid was added to the side chain of lysine to synthesize sulfonated PAs. A lysine residue with 4-methytrityl (Mtt) side-chain protection was used for selective deprotection of amine groups. Mtt removal was performed by shaking resins for $5 \mathrm{~min}$ with TFA/TIS/ $\mathrm{H}_{2} \mathrm{O} / \mathrm{DCM}$ in the ratio of
5:2.5:2.5:90. Cleavage of the PAs from the resin was carried out with a mixture of TFA/TIS $/ \mathrm{H}_{2} \mathrm{O}$ in the ratio of $95: 2.5: 2.5$ for $2 \mathrm{~h}$. Excess TFA was removed by rotary evaporation. The remaining viscous PA solution was triturated with ice-cold ether, and the resulting white precipitate was dried under vacuum. PAs were characterized by liquid chromatography-mass spectrometry (LC-MS). Mass spectrum was obtained with Agilent 1200 LC-MS equipped with Agilent 6530 Q-TOF with an ESI source and Zorbax Extend-C18 $2.1 \times 50 \mathrm{~mm}$ column for basic conditions and Zorbax SB-C8 $4.6 \mathrm{~mm} \times 100 \mathrm{~mm}$ column for acidic conditions. A gradient of (a) water $\left(0.1 \%\right.$ formic acid or $\left.0.1 \% \mathrm{NH}_{4} \mathrm{OH}\right)$ and (b) acetonitrile ( $0.1 \%$ formic acid or $\left.0.1 \% \mathrm{NH}_{4} \mathrm{OH}\right)$ was used. Agilent 1200 preparative reverse-phase HPLC system equipped with a Zorbax Extend-C18 $21.2 \times 150 \mathrm{~mm}$ column for basic conditions and a Zorbax SB-C8 $21.2 \times 150 \mathrm{~mm}$ column for acidic conditions was used to purify the peptides. A gradient of (a) water ( $0.1 \%$ TFA or $0.1 \%$ $\left.\mathrm{NH}_{4} \mathrm{OH}\right)$ and (b) acetonitrile (0.1\% TFA or $\left.0.1 \% \mathrm{NH}_{4} \mathrm{OH}\right)$ was used.

Peptide Amphiphile Nanofiber Formation. To investigate angiogenic potentials of PA nanofibers presenting heparin-mimicking functional groups, we designed and synthesized several PA molecules. Functional group content varied for each molecule: Heparin-mimetic PA was synthesized with sulfonate, hydroxyl, and carboxylic acid groups, $\mathrm{SO}_{3}$-PA with sulfonate and carboxylic acid groups, and Asp-PA with only carboxylic acid groups (Figure 1). To induce gel and nanofiber formation, we prepared PA formulations by mixing Heparin-mimetic PA, Asp-PA, and $\mathrm{SO}_{3}$-PA molecules with Lys-PA at 1:2, 1:1, and 1:1 molar ratios, respectively. His-PA solution was adjusted to $\mathrm{pH} 7.4$, and heparin was mixed with Lys-PA at $\sim 1: 8$ molar ratios.

AFM Imaging of PA Nanofibers. AFM sample solutions were dropped on the silicon wafer surface and mixed by pipetting up and down. We mixed $25 \mu \mathrm{L}$ of $0.02 \mathrm{wt} \%$ Heparin-mimetic PA or equimolar concentrations of $\mathrm{SO}_{3}$-PA and Asp-PA with $25 \mu \mathrm{L}$ of 0.02 wt \% positively charged Lys-PA. Heparin was mixed with Lys-PA, and His-PA solution was adjusted to $\mathrm{pH} 7$ for nanofiber formation. After $30 \mathrm{~s}$, solvent on the wafer was removed by using dust-free tissue paper, and the rest was airdried. Contact mode atomic force microscopy (AFM) was performed by using model MFP-30 from Asylum Research. All images were taken with $0.5 \mathrm{~Hz}$ scan rate. Tips with resonance frequency of $13 \mathrm{kHz}$ and spring constant of $0.2 \mathrm{~N} / \mathrm{m}$ were used in all experiments.

SEM Imaging of PA Gels. PA gels ( 1 wt \% Heparin-mimetic PA gel and equimolar amount for the rest) were transferred onto a metal mesh, and network dehydration was performed by incubating gels for $30 \mathrm{~s}$ in $20,40,60,80$, and $100 \%$ ethanol sequentially. Then, gels were critical-point dried by using Autosamdri-815B (Tousimis). Dried gels were coated with $6 \mathrm{~nm}$ of Pt. SEM (FEI Quanta 200 FEG) images were taken by using ETD detector at high vacuum mode with $30 \mathrm{keV}$ beam energy.

TEM Imaging of PA Nanofibers and Nanofiber Size Measurements. PA nanofiber size measurements were made according to TEM images for each nanofiber type (Figure 2). ${ }^{25}$ TEM sample was prepared by mixing Heparin-mimetic $\mathrm{PA}, \mathrm{SO}_{3}-\mathrm{PA}$, and Asp-PA (1 wt \%) with Lys-PA (1 wt \%). Gel was diluted 10 times, and $30 \mu \mathrm{L}$ from this solution was dropcasted onto a hydrophobic surface. TEM grid was placed onto droplet and incubated for $3 \mathrm{~min}$. Staining was performed with $2 \%$ uranyl acetate. Nanofiber diameters were measured by Image J software (NIH).

SEM Imaging of Cells on the PA Gels. In vitro tube formation experiment was performed (as described above) on round glass coverslips located in 24-well plates. After $48 \mathrm{~h}$, media on cells were aspirated, and cells were washed with $1 \times$ PBS twice. Cells were fixed with $2 \%$ glutaraldehyde $1 \mathrm{~h}$ prior to fixation with $1 \%$ osmium tetroxide $\left(\mathrm{OsO}_{4}\right)$. After network dehydration, critical-point drying was performed as described above for SEM imaging of PA gels. Samples were coated with $6 \mathrm{~nm} \mathrm{Au}-\mathrm{Pd}$ coating, and SEM imaging was performed as described above. 

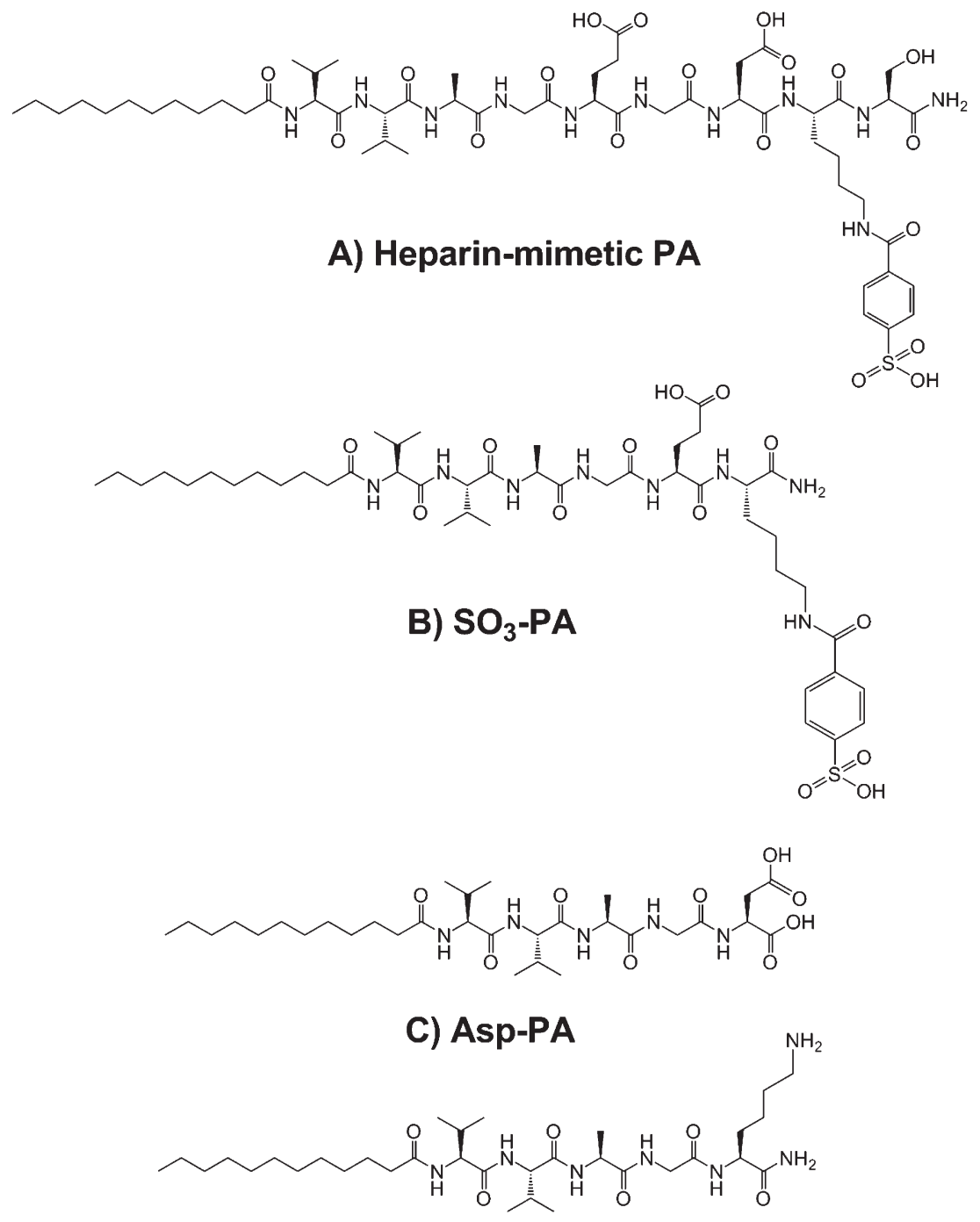

\section{D) Lys-PA}

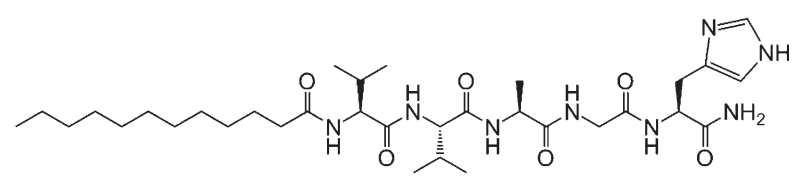

\section{E) His-PA}

Figure 1. Chemical structures of peptide amphiphiles (PAs) used in this study: (A) Heparin-mimetic PA, (B) SO 3 -PA, (C) Asp-PA, (D) Lys-PA, and (E) His-PA.

Isothermal Titration Calorimetry. To investigate the interaction between VEGF and PAs, we used the iTC $_{200}$ system (MicroCal, GE Healthcare). VEGF titration $(6.25 \mu \mathrm{M})$ into four different PA solutions (0.08 $\mathrm{mM})$ was performed on Heparin-mimetic PA (solution form), Heparin-mimetic PA with Lys-PA (nanofiber form), Asp-PA (solution form), and Asp-PA with Lys-PA (nanofiber form). VEGF into $\mathrm{H}_{2} \mathrm{O}$ and $\mathrm{H}_{2} \mathrm{O}$ into Heparin-mimetic PA with Lys-PA titrations were performed as control to eliminate dilution heats. Reaction was performed at $30{ }^{\circ} \mathrm{C}$ with $400 \mathrm{rpm}$ stirring speed. Twenty-five injections were performed, where the injection period was $4 \mathrm{~s}$ and space between injections was 200 s. The data were integrated and fit to a curve with MicroCal Origin software to calculate the binding constant. For VEGF to PA solution titrations, best-fitting was obtained with one set of sites model, whereas for VEGF to PA nanofiber titrations, best-fitting was obtained with sequential binding sites model, and overall binding constant was calculated. To determine supramolecular heparin-mimetic system concentration, we performed calculations based on approximations made by Silva et al. ${ }^{26}$ (average diameter of fiber disk $=6 \mathrm{~nm}$; circumference of nanofiber $(\Pi \mathrm{d})=18.8 \mathrm{~nm}$, number of PA molecules/radial disk $=50$ ). Width of radial disk $\approx$ size of 1 molecule $=18.8 \mathrm{~nm} / 50=0.376 \mathrm{~nm}$. A $100 \mathrm{~nm}$ length PA nanofiber can contain $\sim 13300$ PA molecules with 50 PA molecules per radial disk and $0.376 \mathrm{~nm}$ width.

Heparin mimetic PA and Lys-PA were mixed at 1:2 molar ratio. Therefore, the number of Heparin mimetic PA molecules per $100 \mathrm{~nm}$ 

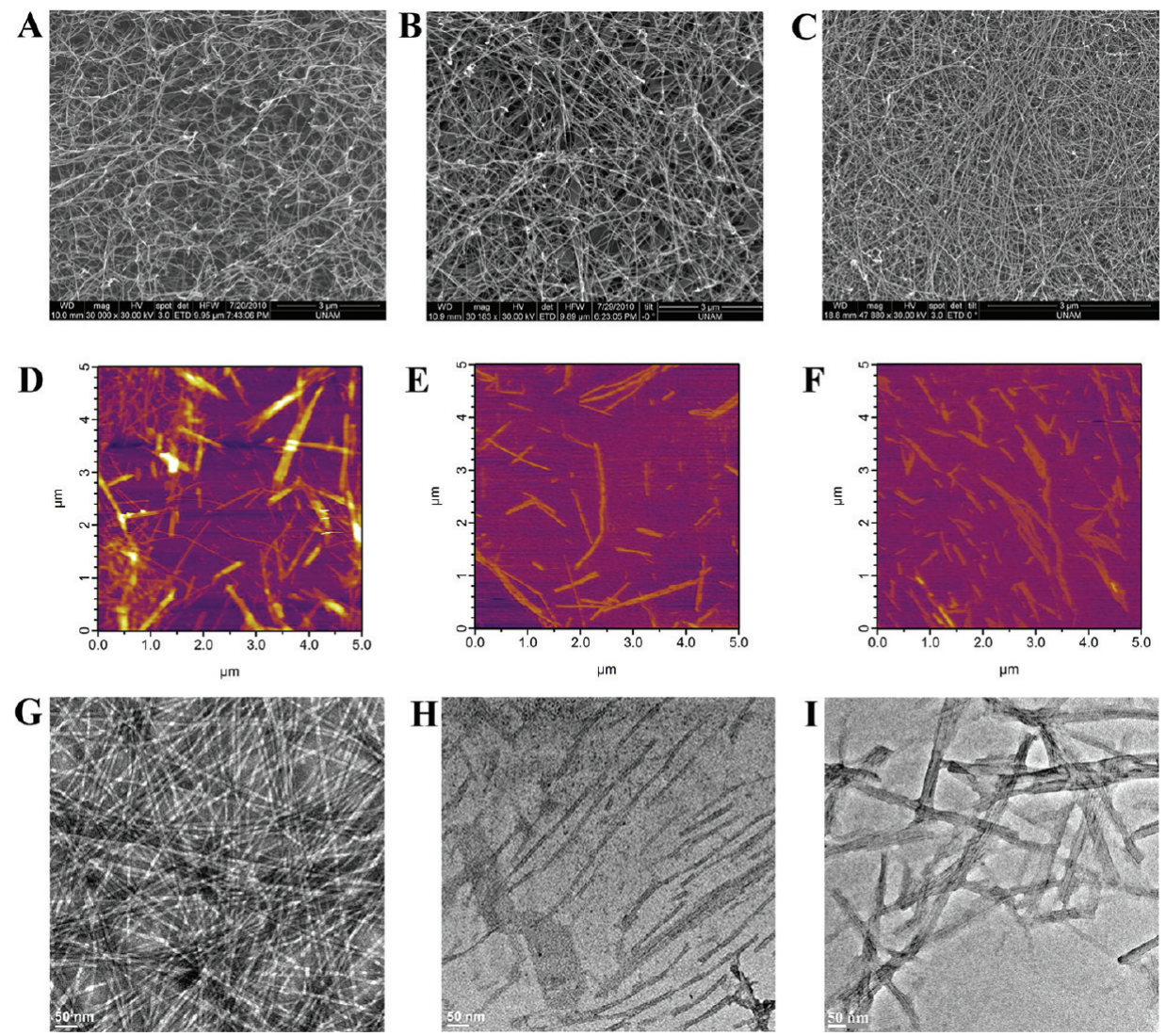

Figure 2. Characterization of peptide amphiphile nanofiber matrices by using SEM, AFM, and TEM. Imaging studies revealed that the gels that were formed by the PA molecules had similar structural properties in terms of individual fibers and formation of nanofibrous networks. SEM images of Heparin-mimetic PA (A), Asp-PA (B), and $\mathrm{SO}_{3}-\mathrm{PA}(\mathrm{C})$. AFM images of Heparin-mimetic PA (D), Asp-PA (E), and SO $\mathrm{S}_{3}$-PA (F). TEM images of Heparin-mimetic PA (G), Asp-PA (H), and $\mathrm{SO}_{3}$-PA (I).

nanofiber was calculated to be $13300 / 3=4433$ molecules. By assuming that the average nanofiber length was $100 \mathrm{~nm}$, nanofiber concentration = $0.08 \mathrm{mM} / 4433=1.8 \times 10^{-5} \mathrm{mM}$. Asp-PA and Lys-PA were mixed with 1:1 molar ratio. The number of Asp-PA per $100 \mathrm{~nm}$ nanofiber was calculated to be $13300 / 2=6650$ molecules. By assuming that average nanofiber length was $100 \mathrm{~nm}$, nanofiber concentration $=0.08 \mathrm{mM} / 6650=$ $1.2 \times 10^{-5} \mathrm{mM}$. The nanofiber dimensions were also measured by using TEM imaging, as described above. All solutions that were used in ITC experiments were at $\mathrm{pH} 7$.

To investigate the interaction between heparin and Lys-PA, heparin $(100 \mu \mathrm{g} / \mathrm{mL})$ was titrated into Lys-PA solution $(40 \mu \mathrm{g} / \mathrm{mL})$. Reaction was performed at $30{ }^{\circ} \mathrm{C}$ with $400 \mathrm{rpm}$ stirring speed. Twenty-five injections were performed, where injection period was $4 \mathrm{~s}$ and space between injections was $150 \mathrm{~s}$. The data were integrated and fit to a curve with MicroCal Origin software to calculate the binding constant. Bestfitting was obtained with one set of sites model.

Oscillatory Rheology. Oscillatory rheology measurements were performed with an Anton Paar Physica RM301 rheometer operating with a $25 \mathrm{~mm}$ parallel plate configuration at $25^{\circ} \mathrm{C}$. Each sample of $180 \mu \mathrm{L}$ total volume with a final PA concentration of $1 \mathrm{wt} \%$ heparin-mimetic PA or equimolar concentrations for other PA molecules was carefully loaded on the center of the lower plate and incubated for $15 \mathrm{~min}$ before measurement. After equilibration, the upper plate was lowered to a gap distance of $0.5 \mathrm{~mm}$. Storage moduli $\left(G^{\prime}\right)$ and loss moduli $\left(G^{\prime \prime}\right)$ values were scanned from 100 to $0.1 \mathrm{rad} / \mathrm{s}$ of angular frequency, with a $0.5 \%$ shear strain.

Circular Dichroism. JASCO J815 CD spectrometer was used at room temperature. We measured $2 \times 10^{-4} \mathrm{M}$ peptide solutions from 300 to $190 \mathrm{~nm}$, data interval and data pitch were $0.1 \mathrm{~nm}$, scanning speed was $100 \mathrm{~nm} / \mathrm{min}$, and all measurements were performed with three accumulations. DIT was selected as $1 \mathrm{~s}$, bandwidth as $1 \mathrm{~nm}$, and the sensitivity was standard. Molar ellipticity was calculated using the equation: $[\theta]=100 \times \theta /(C \times 1)$, where $C$ is the concentration in molar, and $l$ is the cell path length in centimeters. $[\theta]=\theta /(C \times \mathrm{l})=\mathrm{deg} /\left(\mathrm{mol} / 1000 \mathrm{~cm}^{3}\right) \times$

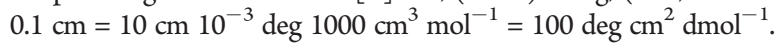

Zeta Potential Measurement. The zeta potential of equimolar PA solutions $(0.16 \mathrm{mM})$ and heparin $(0.5 \mathrm{mg} / \mathrm{mL})$ was measured by Nano-ZS Zetasizer (Malvern). Zeta potential converts measured mobility to zeta potential by using Smoluchowski equation. After measuring zeta potential of each PA solution, Lys-PA was mixed with Heparinmimetic PA (2:1 molar ratio), $\mathrm{SO}_{3}$-PA (1:1 molar ratio), Asp-PA (1:1 ratio), or heparin and the zeta potential of the solution was measured again. Molar ratios were the same as those used for cell culture and other experiments (net -1 charge for each combination).

Cell Lines and Cell Culture Reagents. H5V mouse endothelial cells $^{27}$ were a kind gift from Dr. Annunciata Vecchi, Instituto Clinico Humanitas, IRCCS, Rozzano, Milano, Italy. Human umbilical vein endothelial cells (HUVECs) were donated by Yeditepe University, Istanbul, Turkey. HUVECs were purified as described ${ }^{28}$ and were characterized by staining with CD34, CD31, and CD90 surface markers. These cells were found to be positive for CD31 and CD34 but negative for CD90. All media, sera, and other cell culture reagents were purchased from Invitrogen. Matrigel was purchased from BD Biosciences.

In Vitro Angiogenesis Assay. Equimolar concentrations of PAs (0.2 wt \% for Heparin-mimetic PA and equimolar amount for the rest) were used to form gels in 96-well plates. Coated plates were incubated at $37^{\circ} \mathrm{C}$ for $30 \mathrm{~min}$, prior to overnight incubation in laminar flow hood at 
room temperature for solvent evaporation. The next day, PA matrix formed on 96-well plates was UV-sterilized, and endothelial cells were cultured on these matrices or Matrigel, which was used as a positive control. HUVECs cultured in DMEM with 10\% FBS (growth medium) were collected at $80-90 \%$ confluency and resuspended in DMEM with $5 \%$ FBS for angiogenesis assay. Cell number was adjusted to $2 \times 10^{5}$ cells $/ \mathrm{mL}$, and $200 \mu \mathrm{L}$ of this suspension was added to each well either alone or mixed with low $(10 \mathrm{ng} / \mathrm{mL})$ or high dose $(50 \mathrm{ng} / \mathrm{mL})$ of VEGF/ bFGF combination. After $48 \mathrm{~h}$, cells were imaged by using brightfield microscopy at $100 \times$ magnification. For fluorescence imaging, media over cells were aspirated, and cells were washed with PBS. Calcein solution $(2 \mu \mathrm{M}, 100 \mu \mathrm{L})$ was added to cells and incubated for $30 \mathrm{~min}$ at $37^{\circ} \mathrm{C}$. Cells were imaged with fluorescence microscopy.

Mouse endothelial cells (H5V) were also grown in DMEM with 10\% FBS until 80-90\% confluency. Cells were collected and resuspended in minimal essential media (MEM) with $2 \%$ FBS during angiogenesis assay. Cell numbers were adjusted to $3 \times 10^{5}$ cells $/ \mathrm{mL}$. We added $100 \mu \mathrm{L}$ from this suspension $\left(3 \times 10^{4}\right.$ cells $)$ to each PA matrix either alone or mixed with growth factors (VEGF/bFGF). Cells were incubated for $48 \mathrm{~h}$, and imaging was performed by using bright field microscopy. All of the in vitro experiments and other measurements were performed at least three times.

Cell Proliferation Assay. 96-well plates were coated with PA matrices, as described, or left uncoated (TCP). HUVEC $\left(1 \times 10^{4}\right)$ were added to each well in DMEM with 10\% FBS. BrdU-based kit (Roche) was used to evaluate cell proliferation at the end of $54 \mathrm{~h}$. In brief, $16 \mathrm{~h}$ before ending an experiment, BrdU was added to each well. After $16 \mathrm{~h}$, cells were fixed and stained by using labeled antibody against BrdU. Cells were washed three times with PBS, and substrate solution was added. After 5, 10, and $20 \mathrm{~min}$, color development was measured at $370 \mathrm{~nm}$ by using microplate reader (Molecular Devices) and subtracted from reference wavelength (492 $\mathrm{nm}$ ) values.

Quantification of in Vitro Tube Formation. In total, 12 images $(100 \times$ magnification) were taken for each treatment group (four different images per well). Quantification of endothelial tube lengths on each image was performed by using NIH Image J software according to previously published criteria. ${ }^{29}$ Tube length values obtained for each well (three wells per treatment group) were summed, and mean value of data obtained from three wells was calculated. Two-way ANOVA was used for statistical analysis.

Growth Factor Release from PA Gels. Heparin-mimetic PA, Asp-PA, and heparin solutions were combined with Lys-PA (premixed with $100 \mathrm{ng}$ of VEGF) to induce gel formation (1 wt \% for Heparinmimetic PA gel and equimolar amount for the rest). After $1 \mathrm{~h}$ of incubation at $37^{\circ} \mathrm{C}, 250 \mu \mathrm{L}$ of $1 \times$ PBS was added to each gel. Buffer over gels was collected and replaced with fresh buffer at four different time points $(2,24,72$, and $168 \mathrm{~h})$. VEGF released in the buffer solutions were quantified by ELISA method. VEGF incubated in same buffer solution (without gel) was accepted as $100 \%$ release.

Real-Time Gene Expression Study. HUVECs $\left(3 \times 10^{5}\right.$ cells/ well) were cultured on bare tissue culture plate (NC), Heparin-mimetic PA, or Asp-PA nanofiber matrices (as described in the In Vitro Angiogenesis Assay section) for three different durations (6, 24, and $48 \mathrm{~h}$ ). Total RNAs were extracted from cells by using TRIzol (Invitrogen) according to the manufacturer's instructions. Concentration and purity of isolated RNAs were measured by Nanodrop. Samples were diluted to a concentration of $50 \mathrm{ng} / \mu \mathrm{L}$ prior to their use. RNAs were converted to cDNA and amplified by using SuperScript III Platinum SYBR green one step qRT-PCR Kit (Invitrogen). Primer sequences for each gene are given in Table S3 of the Supporting Information. Specificity of amplifications was determined by the presence of single peaks/gene in melting curve analysis and detection of the product size by running PCR products in $1.5 \%$ agarose gel. Gene expression levels were normalized with GAPDH expressions for each sample, and relative expressions were calculated by $2^{-\Delta \Delta C t}$ method according to the below formula: $\Delta C t(\mathrm{NC})=$ $\left(C t_{\text {gene }}-C t_{\text {reference }}\right) ; \Delta C t($ PA-coated $)=\left(C t_{\text {gene }}-C t_{\text {reference }}\right) ; \Delta \Delta C t=$ $\Delta C t$ (PA nanofiber-coated) $-\Delta C t(\mathrm{NC})$; fold expression $=2^{-\Delta \Delta C t} ; \%$ change in expression: $100 \times 2^{-\Delta \Delta C t}$.

Detection of VEGF Secretion by Endothelial Cells. HUVECs were cultured at a density of $4 \times 10^{4}$ cells/well on different PA matrices and bare tissue culture plates, as described above (In Vitro Angiogenesis Assay section). Supernatants were collected at three different time points $(12,24$, and $48 \mathrm{~h})$. Concentration of VEGF in these supernatants was quantified by ELISA method (Invitrogen). Two-way ANOVA was used to determine the significance of difference between VEGF secretion amount from cells cultured on PA matrices or tissue culture plate.

In Vivo Corneal Micropocket Angiogenesis Assay. Animal model and experimental setup were approved by the Animal Ethics Committee of Fatih University Medical School. The in vivo assay was carried out with 200-220 g female Sprague-Dawley rats. A surgical micropocket was opened in the cornea $\sim 1.5 \mathrm{~mm}$ from the limbus under anesthesia, as described. ${ }^{13}$ Three conditions were tested with this model: 1 wt \% Heparin-mimetic PA gel with 10 ng bFGF and VEGF; growth factor solution including $10 \mathrm{ng}$ bFGF and VEGF; and 1 wt \% Heparin-mimetic PA gel without growth factors. Gels were made in situ by mixing Heparin-mimetic PA and Lys-PA. Eleven days after injection, rats were anesthetized with xylazine/ketamine solution and perfused through injection of India ink to the left ventricular region of their hearts to observe integration of newly formed vessels into the circulatory system. Quantification of vascularization as a response to each treatment ( $n=3$ per group) was done with NIH Image J software according to previous work. ${ }^{13}$ Student's $t$ test was used for statistical analysis of difference between treatment groups. DC-1 digital camera (Topcon Europe, Ijssel, The Netherlands) was used for imaging the cornea.

\section{RESULTS AND DISCUSSION}

To recapitulate natural extracellular environment that induces angiogenesis, we designed PA molecules that can mimic GAG molecules to enable enhanced functioning of the growth factors that are crucial for angiogenesis. Heparin-mimetic PA molecule is decorated with carboxylic acid, hydroxyl, and sulfonate groups to mimic heparin (Figure 1a and Figure S1a of the Supporting Information). To assess the importance of each of these functional groups during angiogenesis process, we synthesized other PA molecules that contain only one or two of these groups. $\mathrm{SO}_{3}$ PA and Asp-PA were designed to control the bioactivity of sulfonate groups and carboxylic acid groups, respectively (Figure 1b,c). His$\mathrm{PA}$ was designed as a neutral PA molecule at physiological $\mathrm{pH}$ to control the effect of a nonbioactive PA gel during angiogenesis (Figure 1e), and heparin was mixed with Lys-PA (Lys-PA/ heparin) to observe the effect of heparin on bioactivity of the PA gel (Figure 1d). All PA molecules were purified with HPLC (Figure S1b, S2a, S3a, S4a, and S5a of the Supporting Information) and inspected with mass spectrometry (Figures S1c, S2b, S3b, $S 4 b$, and S5b of the Supporting Information). The abilities of these molecules to form a network, that can mimic the structural properties of the natural ECM, ${ }^{30}$ were analyzed by SEM imaging. All PA molecules that were analyzed exhibited a nanofibrous network that is suitable for providing the necessary mechanical support for cells (Figure 2a-c and Figure S6a,b of the Supporting Information). AFM imaging of these nanofibrous structures enabled visualization of the nanofibers that make up these ECMlike networks (Figure 2d-f and Figure S6c,d of the Supporting Information). The nanofibers formed by PA molecules were also imaged by AFM and TEM (Figure 2 and ref 25). Nanofiber sizes for different PA combinations are provided in Table S1 
of the Supporting Information. Nanofiber diameters for Heparinmimetic PA/Lys-PA, Asp-PA/Lys-PA, Lys-PA/heparin, and HisPA samples do not differ significantly.

Mechanical properties of the extracellular environment are crucial for determining cell fate, and thus we compared the
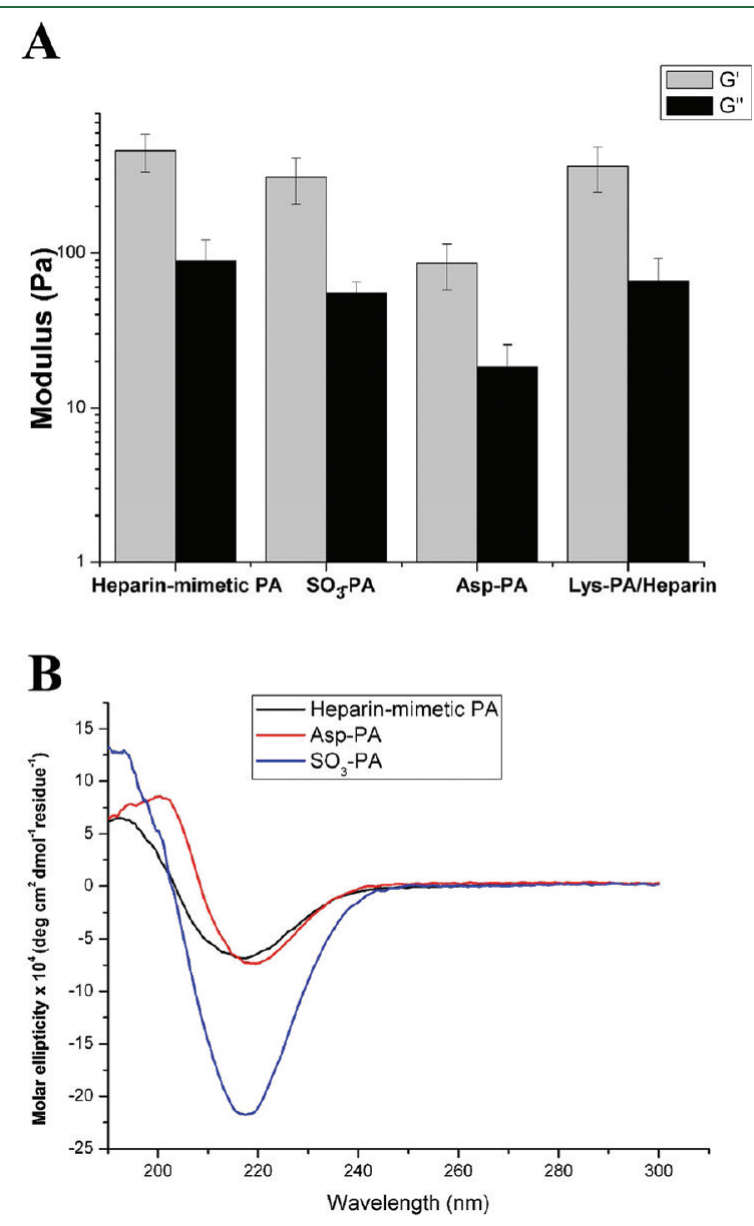

Figure 3. (A) Rheology measurements. Storage and loss moduli of equimolar PA gels that were measured with oscillatory rheometry, revealed that the mechanical properties of the gels were similar. (B) Circular dichroism analysis. Circular dichroism spectra of Heparinmimetic PA and Asp-PA molecules mixed with Lys-PA show characteristic $\beta$-sheet structure in all of the samples. gels by using oscillatory rheology to understand whether the differences in their bioactivities were caused by variations in their mechanical properties (Figure 3a). Each of the gels (Heparin-mimetic PA/Lys-PA gel, $\mathrm{SO}_{3}$-PA/Lys-PA gel, AspPA/Lys-PA gel, and Lys-PA/heparin gel) had storage modulus $\left(G^{\prime}\right)$ higher than loss modulus $\left(G^{\prime \prime}\right)$, indicating gel formation. Storage moduli, showing stiffness of the gels, were in the same order of magnitude for all gels designed for this study. Furthermore, loss tangents $\left(\tan \delta=G^{\prime \prime} / G^{\prime}\right)$ of all materials were compared, which provides information about viscoelastic character of the gels and their gelation properties. ${ }^{31,32}$ These values were found to be comparable in all of the PA gels tested here (Table S2 of the Supporting Information). Structural properties of the gels were also analyzed with circular dichroism (CD) spectroscopy. The CD spectra of all of the PAs demonstrated $\beta$-sheet secondary structure (Figure $3 \mathrm{~b}$ ). Therefore, the structural properties of the gels were found to be comparable as well.

Zeta potentials for PA solutions were measured to understand the charge of the peptide systems. Zeta potentials of the PA solutions were measured, and the self-assembled nanostructures were measured upon the addition of oppositely charged Lys-PA (Figure S14 of the Supporting Information). All carboxylate and sulfonate functionalized PAs and heparin revealed negative potentials. When Lys-PA solution with a positive potential was added to the aforementioned solutions, overall charge in all solutions revealed negative potentials. Molar ratios of these mixtures were adjusted so that net charge of the system will be negative. Heparin-mimetic PA/Lys-PA and $\mathrm{SO}_{3}$-PA/Lys-PA combinations had similar potentials, nearly $-30 \mathrm{mV}$, whereas Asp-PA/ Lys-PA potential decreased to $-5 \mathrm{mV}$. We observed a similar trend in heparin and Lys-PA mixture, where potential of heparin solution decreased from -60 to $-45 \mathrm{mV}$. This observation can be related to the presence of sulfonate $\left(-\mathrm{SO}_{3}\right)$ group in Heparinmimetic $\mathrm{PA}, \mathrm{SO}_{3}-\mathrm{PA}$, and heparin. Sulfonate group's $\mathrm{p} K_{\mathrm{a}}(\sim 1)$ is lower than carboxylate group's $(\sim 5)$, making charge neutralization of Asp-PA easier than that of sulfonate-bearing PAs. Therefore, the presence of sulfonate group increases the negative charge density on PA nanofibers, which might have an activatory role in growth factor binding. However, $\mathrm{SO}_{3}$-PA nanofibers and heparin/Lys-PA did not reveal bioactivity compared with Heparin-mimetic PA nanofibers, as discussed below. Therefore, the specificity of growth factor binding to PA nanofibers is not only related to the charge of the system. Moreover, growth factor release rates from Lys-PA/heparin gel shown in Figure 8 were
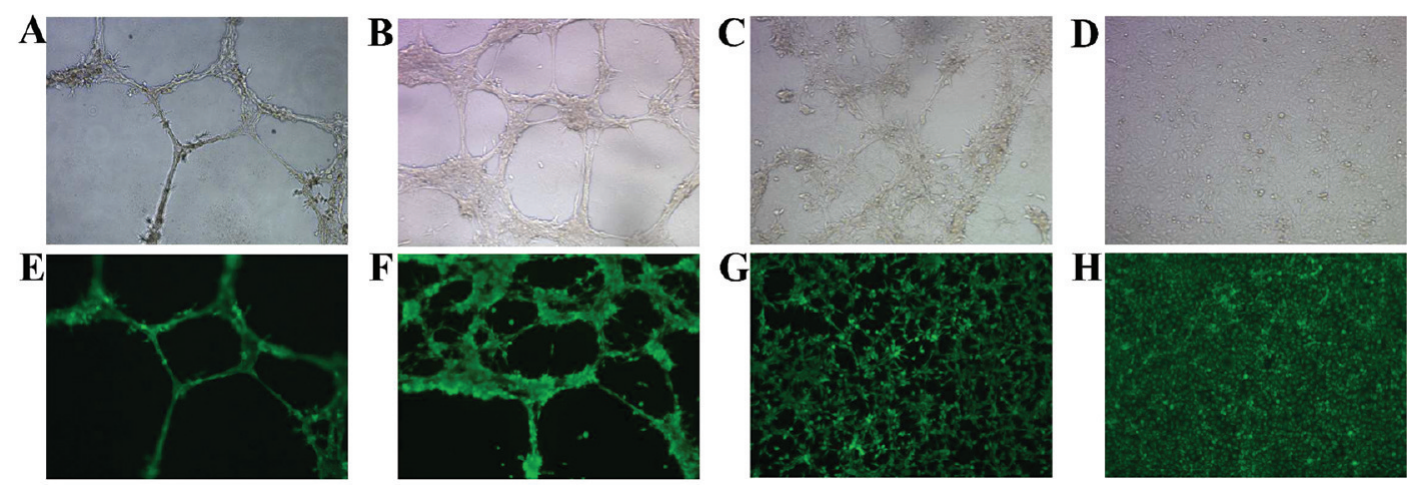

Figure 4. In vitro angiogenesis assay. Bright-field images of HUVECs were cultured on Matrigel (A), Heparin-mimetic PA nanofiber matrix (B), AspPA nanofiber matrix (C), and bare tissue culture plate (D) and followed for $48 \mathrm{~h}$ to assess migration and tube formation. Live-dead assays revealed that HUVECs grown on these matrices showed similar viability profiles: matrigel (E), Heparin-mimetic PA nanofiber matrix (F), Asp-PA nanofiber matrix $(\mathrm{G})$, and bare tissue culture plate $(\mathrm{H})$. All images were taken at $100 \times$ magnification. ( $n=3$ for all conditions). 
significantly faster than those from Heparin-mimetic PA gel and Asp-PA gel, which is also related to specificity of the nanofiber and growth factor interactions.

The angiogenic potential of the heparin-mimicking peptide nanofibers was investigated by culturing HUVECs on PA nanofibers decorated with functional groups inspired by heparin (Figure 4). When HUVECs are cultured on basement membrane gel, which consists of natural ECM proteins as well as various growth factors (Matrigel), cells coalesce on the matrix forming capillary-like structures (Figure 4a). Cells cultured on Heparinmimetic PA (Figure 4b) matrix also formed capillary-like structures; however, although this matrix is synthetic and does not contain any growth factors or GAG molecules, no addition of exogenous growth factors was needed for the formation of these capillary-like structures. ${ }^{33} \mathrm{SO}_{3}$-PA and Asp-PA matrices slightly induced migration of cells compared with Heparin-mimetic PA, forming a few tube-like structures (Figure 4c and Figure S7 of the Supporting Information). Lys-PA/heparin and His-PA matrices did not induce any angiogenic activity, where cells on these matrices acted similar to cells on bare tissue culture plates (Figure $4 \mathrm{~d}$ and Figure S7 of the Supporting Information). The lack of angiogenic activity on His-PA matrices shows that the uncharged nanofiber structure is not a determinant for induction of angiogenesis. Cells were also stained with Calcein AM, which is degraded in metabolically active cells producing fluorescence. This assay revealed that the cells that formed capillary-like structures as well as the cells that were cultured on basement membrane, control PA gels, and tissue culture plate were metabolically active (Figure $4 \mathrm{e}-\mathrm{h}$ ).

To analyze whether Heparin-mimetic PA had any effect on proliferation of endothelial cells, BrdU-based proliferation assay was used (Figure S9 of the Supporting Information). The results revealed that all of the PA nanofibers utilized in this study exhibited similar effect on the proliferation rates of endothelial cells compared with that of tissue culture plate. Therefore, it can be concluded that Heparin-mimetic PA induces cellular migration, sprouting, and tube formation by the endothelial cells, however, neither induces nor impedes cellular proliferation.

When average lengths of the capillary-like formations were quantified, Heparin-mimetic PA matrix was found to be the most effective matrix for angiogenesis formation compared with basement membrane and other controls. Among the two most potent matrices, Heparin-mimetic PA and Asp-PA, Heparin-mimetic PA enhanced tube formation capability of HUVECs nearly four times more than Asp-PA (Figure 5). The other PA nanofibers also demonstrated poor angiogenesis activity because of the deficiency of functional groups (Figure S7 of the Supporting Information). The lack of angiogenic activity observed on Lys-PA/heparin matrices is potentially due to suppression of heparin's bioactivity because of nonspecific electrostatic binding. Similar nonspecific binding between lysine-containing PA molecules and heparin was previously observed. ${ }^{14}$ In that study, scrambled PA molecule with several lysine residues was shown to bind to heparin nonspecifically, masking heparin's bioactivity. The interaction between the Lys-PA and heparin was also observed by ITC measurement (Figure S12 of the Supporting Information). The binding interaction between Lys-PA and heparin was driven mainly by enthalpic reactions $(\Delta H=-7.2 \times$ $\left.10^{5} \pm 5.1 \times 10^{4}, \Delta S=-2390\right)$ similar to the scrambled PA molecule and heparin observed by Rajangam et al. ${ }^{14}$ The addition of exogenous growth factor combination (VEGF/FGF-2) to the culture media did not change tube formation potential of any of

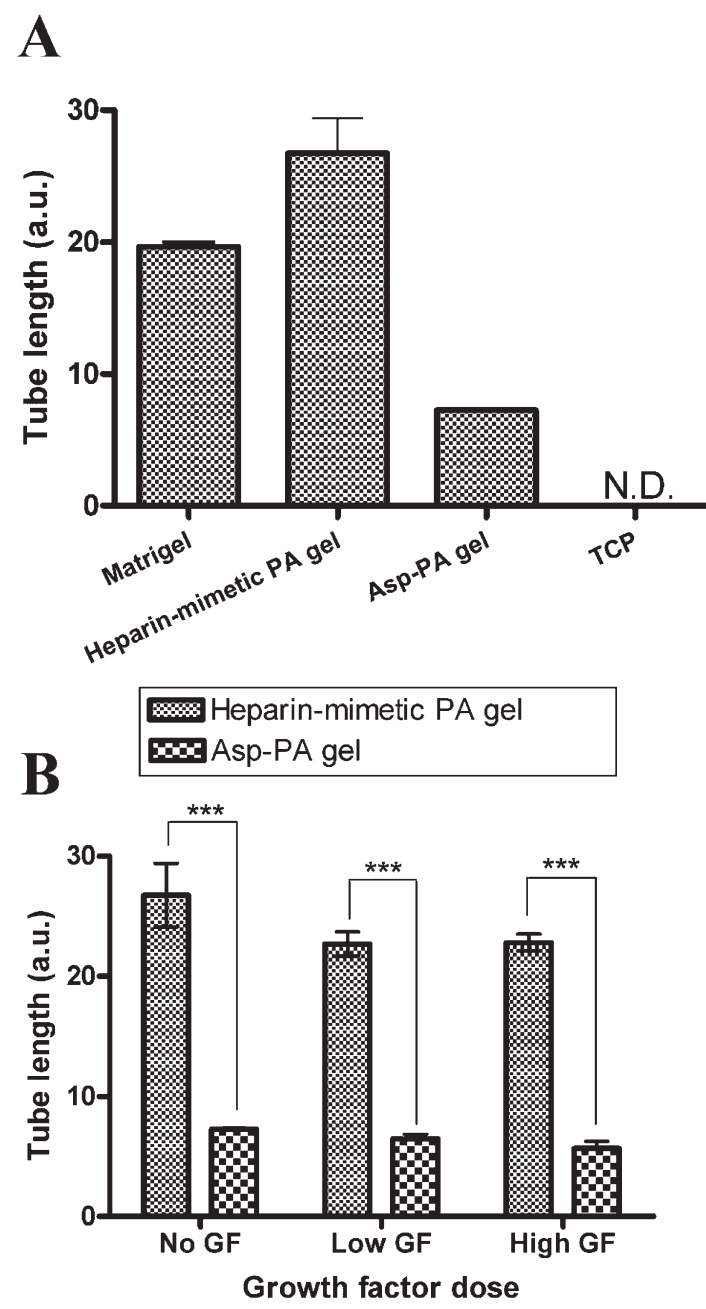

Figure 5. Quantification of tube lengths formed by endothelial cells (HUVECs). (A) Quantification of tube lengths by HUVEC cultures on Matrigel, Heparin-mimetic PA gel, Asp-PA gel, or tissue culture plate (TCP). Statistical differences between groups were analyzed by one-way ANOVA test. Bonferroni's multiple comparison test was used as posthoc analysis. $p<0.001$ between Heparin-mimetic PA gel and Asp-PA gel or TCP. $p<0.05$ between Heparin-mimetic PA gel and Matrigel. (B) Graph illustrates quantification of tube lengths for different growth factor treatment conditions (most potent two scaffolds are shown). Low dose: $10 \mathrm{ng} / \mathrm{mL}$ VEGF/FGF-2, high dose: $50 \mathrm{ng} / \mathrm{mL}$ VEGF/FGF-2. $p<$ 0.001 between Heparin-mimetic PA and Asp-PA scaffolds (analyzed by two-way ANOVA) ( $n=3$ for all conditions).

the other matrices, which indicates that presence of a fibrous matrix and growth factors are not sufficient for angiogenesis (Figure 5B and Figure S7 of the Supporting Information). Previously, a difference in angiogenic activity between a heparin-binding PA and its scrambled sequence was also observed, emphasizing the importance of appropriate presentation of heparin to growth factors and cells. ${ }^{14}$

In vitro tube formation potential of Heparin-mimetic PA nanofiber matrix was further investigated by using H5V cell line (mouse endothelial cell line). ${ }^{27}$ Similar to HUVECs, H5V cells also formed capillary-like structures on Heparin-mimetic PA matrices after $24 \mathrm{~h}$ of culturing, whereas they did not form tubes on Asp-PA and $\mathrm{SO}_{3^{-}}$ PA matrices (Figure S8 of the Supporting Information). These results suggest that the presence of all three functional groups in Heparin-mimetic PA is necessary for in vitro angiogenesis formation. 

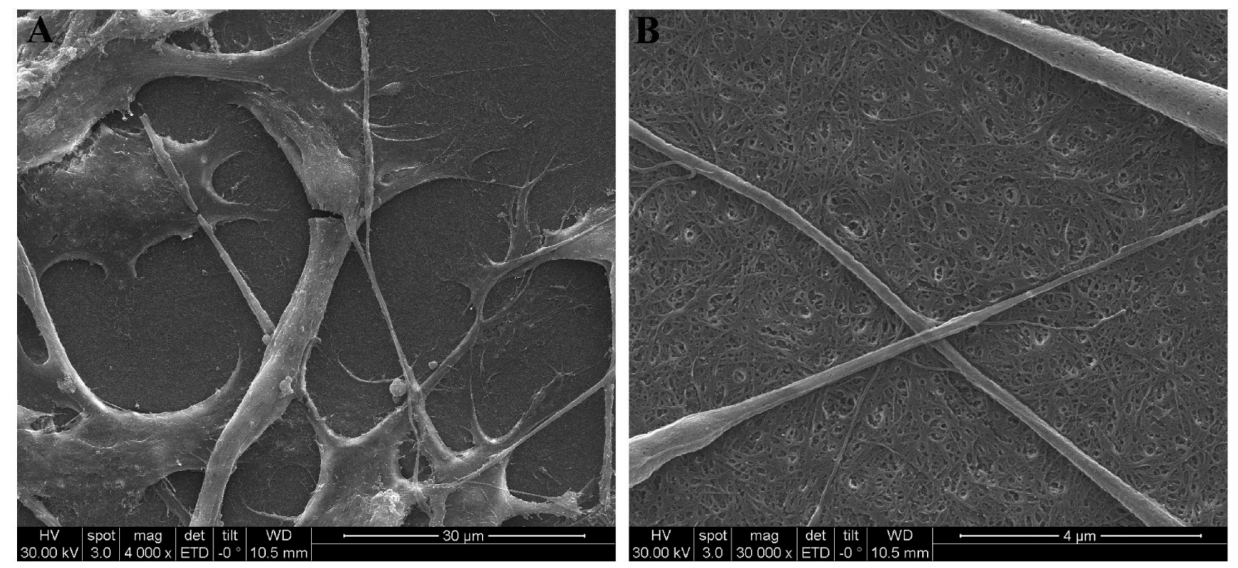

Figure 6. Electron micrographs of endothelial sprouting and tube formation on Heparin-mimetic PA matrix. (A) Cells interact with the fibrous network and form polygonal structures. (B) Endothelial sproutings on PA matrix.

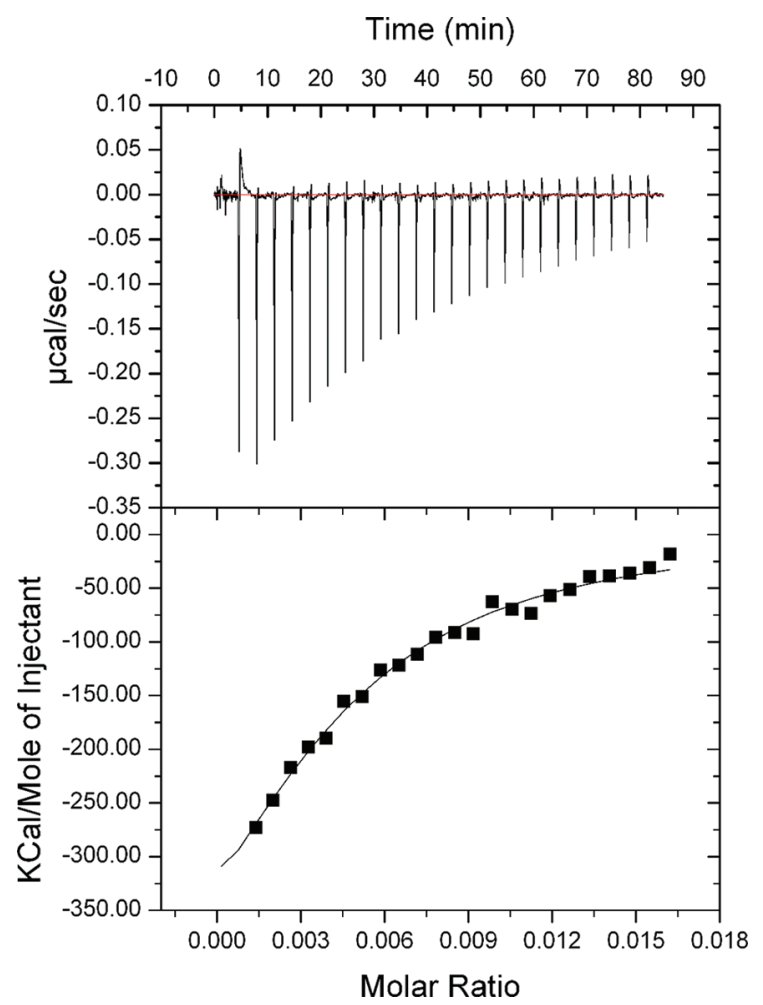

Figure 7. Calorimetric determination of interaction between Heparinmimetic PA and VEGF. Isothermal titration calorimetry was used to measure binding affinity of Heparin-mimetic PA with VEGF. The top graph shows heat change per unit time during VEGF titration into Heparin-mimetic PA solution, and the bottom graph displays the integrated data (filled squares) and the best fit to a nonlinear function assuming one set of binding sites. $K_{\mathrm{a}}$ calculated $=2.93 \times 10^{6} \pm 5.12 \times$ $10^{5} \mathrm{M}^{-1}$.

The cells on PA matrices were also imaged by SEM to analyze the effects of Heparin-mimetic PA nanofibers on endothelial cells (Figure 6, Figure S10 of the Supporting Information). The Heparin-mimetic PA matrix was observed to facilitate cell attachment and spreading compared with cells grown on tissue culture plate (Figure 6 and Figure S10 of the Supporting Information). ${ }^{34}$ Moreover, Heparin-mimetic PA matrix allowed

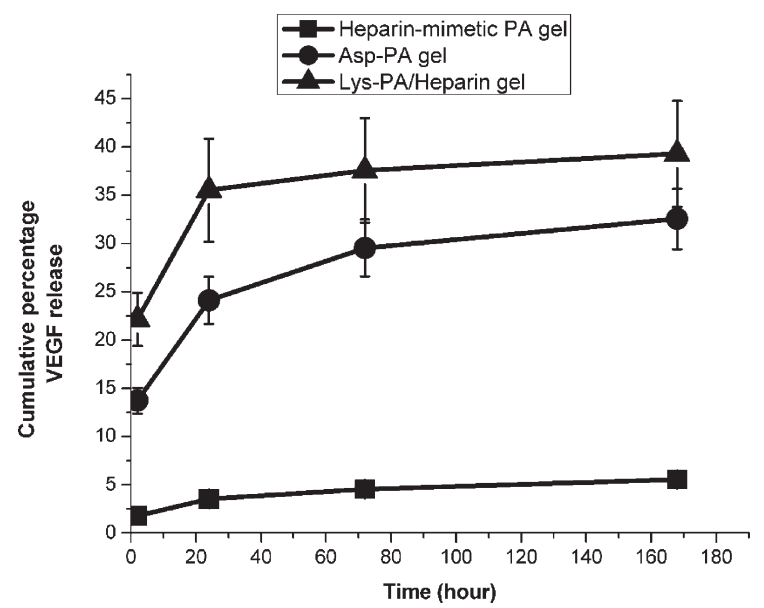

Figure 8. Slow release of growth factor from Heparin-mimetic PA gel. Release of VEGF from 3 different PA gels were measured for 7 days. VEGF concentration in release buffer was measured by ELISA method (Bars indicate SEM for each group). ( $n=5$ for Heparin-mimetic PA; $n=$ 3 Asp-PA and Lys-PA/heparin).

cell-cell interactions and polygonal structure formation, which is a characteristic sign of in vitro angiogenesis (Figure 6). ${ }^{35}$ Endothelial sprouting and tubules extending on and inside the PA matrix further support the suitability of Heparin-mimetic PA matrix for endothelial cell activities (Figure 6 and Figure S10 of the Supporting Information).

As previously mentioned, glycosaminoglycans regulate growth factor-receptor interactions in the natural cellular environment. For example, VEGF cannot affect endothelial cells when there is no glycosaminoglycan in the microenvironment. ${ }^{711}$ Therefore, induction of angiogenesis by Heparin-mimetic PA nanofibers is potentially caused by their ability to bind to and present the growth factors that are secreted by the endothelial cells, which is critical for long-lasting angiogenic signaling process. ${ }^{11}$ Specific growth factor binding to Heparin-mimetic PA nanofibers was investigated by isothermal titration calorimetry (ITC), where heat change was measured after titrating VEGF molecules into the PA solutions (Figure 7 and Figure S11 of the Supporting Information). The binding constants between VEGF and both solution and nanofiber forms of Heparin-mimetic PA and Asp-PA 
were calculated by ITC (Figure 7, Figure S11 and Table S3 of the Supporting Information). As a result of this experiment, binding constant between Heparin-mimetic PA and VEGF was found to be similar to the binding constant between heparin and VEGF, which confirms high affinity of Heparin-mimetic PA molecules to VEGF. Binding constants of both solution and nanofiber forms of PAs with VEGF were comparable as well. In addition, both Heparin-mimetic PA and Asp-PA molecules revealed similar binding affinity to VEGF. This suggests that VEGF-PA interaction at this concentration was due to electrostatic and noncovalent interactions. Moreover, VEGF binding was driven by large enthalpic changes, which also shows that hydrogen bonding, electrostatic, and van der Waals interactions between functional groups have taken a role in the VEGF-PA interaction (Table S3 of the Supporting Information). ${ }^{36}$ The decrease in entropy indicates the loss of conformational freedom for interacting molecules and the formation of more ordered complex structures (Figure 7, Figure S11 and Table S3 of the Supporting Information). ${ }^{37}$

To investigate further the interaction of VEGF with the nanofiber network formed by PA molecules, we designed a growth factor release assay by adding VEGF to gels formed by the PA nanofibers. VEGF release from Heparin-mimetic PA, Asp-PA, and Lys-PA/heparin gels were monitored for 7 days to analyze the release rate. We observed burst release of growth factors from Asp-PA and heparin gels at $2 \mathrm{~h}$, whereas the release rate was significantly lower for Heparin-mimetic PA gels (Figure 8). At the end of 7 days, only $\sim 5 \%$ of the encapsulated VEGF was released from Heparin-mimetic PA gel, whereas this ratio was nearly $40 \%$ for heparin gel and 33\% for Asp-PA gel. Because gelation and structural properties of the PA molecules revealed no significant differences, as analyzed by SEM, AFM, rheology, and $\mathrm{CD}$, the possibility of physical release causing differential release from Heparin-mimetic PA gel and other gels was eliminated. We concluded that VEGF binds to Heparinmimetic PA nanofibers more strongly than Asp-PA and Lys-PA/ heparin nanofibers. Although ITC results revealed similar binding affinities for both Heparin-mimetic PA and Asp-PA molecules to VEGF (Table S3 of the Supporting Information), where these molecules are used in very dilute amounts $\left(\sim 10^{-4} \mathrm{M}\right)$, the release of the VEGF from the corresponding gels, which are composed of densely packed nanofibers, was significantly different (Figure 8). According to the results of the release assay, it can be suggested that Heparin-mimetic PA nanofibers provide more specific binding sites for growth factors compared with Asp-PA nanofibers. The release profile of VEGF from Lys-PA/ heparin gel further demonstrates the suppression of growth factor binding capacity of heparin in this gel, which we have previously hypothesized according to the results of the in vitro angiogenesis assay (Figure 4 and Figure S7 of the Supporting Information). Importantly, slow release rate of VEGF from Heparinmimetic PA gel is a significant finding because the formation of robust vessels requires long-term release of growth factors at low concentrations. ${ }^{24,38}$ Growth factor concentrations above the microenvironmental threshold (therapeutic range) cause vessel malformation with leaky and aberrant character. ${ }^{24,38,39}$ Heparin-mimetic PA gel was observed to release VEGF within the narrow therapeutic range, which is important for clinical applications.

Angiogenesis is initiated and maintained through distinct regulatory mechanisms that take place inside the endothelial cells. Toward this purpose, phases of endothelial cell activation and proliferation, followed by cellular migration and finally stabilization of tubular structures are required. Expressions of

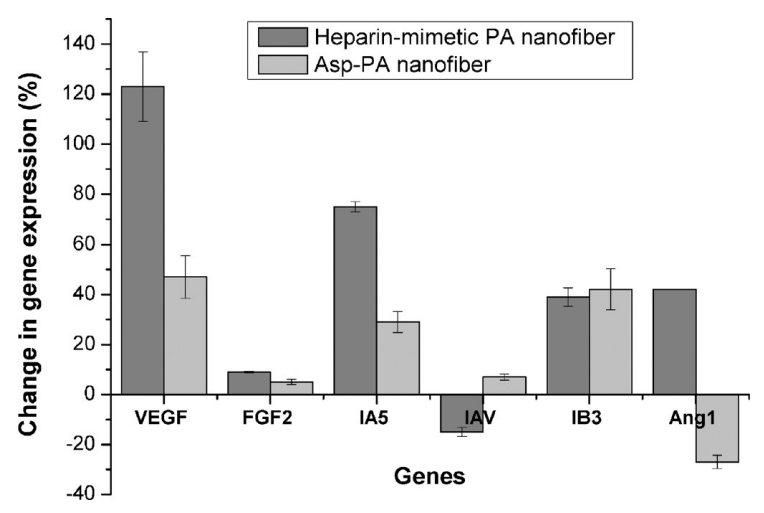

Figure 9. Investigation of expression profiles of angiogenic genes in endothelial cells (HUVEC) on Heparin-mimetic PA matrices and tissue culture plate. Expression profiles of genes involved in different angiogenic stages were investigated at different time points by qRT-PCR. Activities of PA matrices tested here were compared with tissue culture plate, and results are illustrated as change in gene expression (\%). Peak time point was selected for each gene and shown in this Figure $(n=3$ for all experiments).

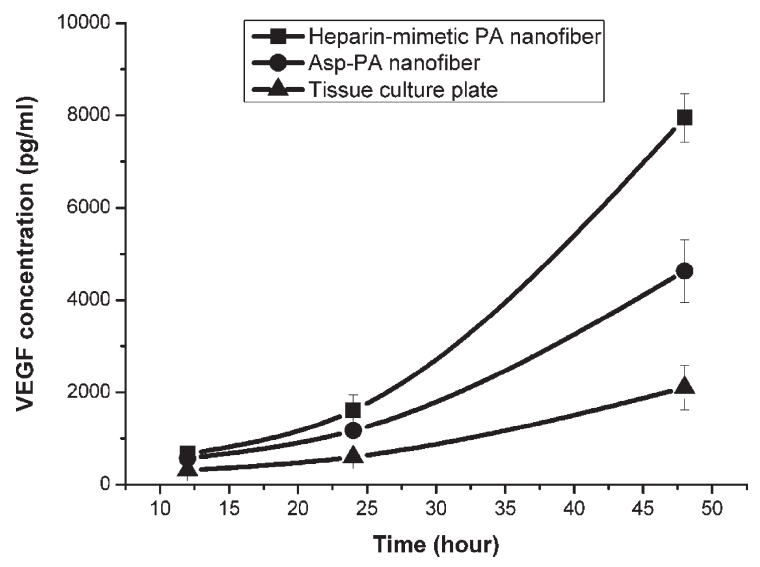

Figure 10. Determination of VEGF secretion from endothelial cells (HUVECs) cultured on PA matrices or tissue culture plate. Timedependent VEGF secretion from HUVECs cultured on different PA matrices or tissue culture plate were measured by using the ELISA method. $p<0.001$ between Heparin-mimetic PA and Asp-PA or tissue culture plate at $48 \mathrm{~h}$ (analyzed by two-way ANOVA) ( $n=3$ for all conditions).

several genes are strictly regulated during these phases. To investigate further the mechanism of angiogenic switch in endothelial cells caused by Heparin-mimetic PA nanofibers, we analyzed the expression of genes involved in angiogenesis at mRNA level. Six different genes were selected from three different stages of angiogenesis. VEGF and FGF-2 are mainly involved in endothelial cell activation and proliferation; integrin $\alpha 5$ (IA5), integrin $\alpha \mathrm{v}$ (IAV), and integrin $\beta 3$ (IB3) take roles in cellular migration, and angiopoietin-1 (Ang-1) induces stabilization of vascular tubes. ${ }^{40}$ Endothelial cells were cultured on PA matrices for three different durations $(6,24$, and $48 \mathrm{~h})$ to simulate sequential activation of angiogenic stages in natural environment. During the natural course of angiogenesis, VEGF and FGF-2 are upregulated at $6 \mathrm{~h}$, integrins at $24 \mathrm{~h}$, and Ang- 1 at $48 \mathrm{~h}$ (Table S4 of the Supporting Information). Figure 9 shows peak points of timedependent transcription of each gene, where each PA treatment 

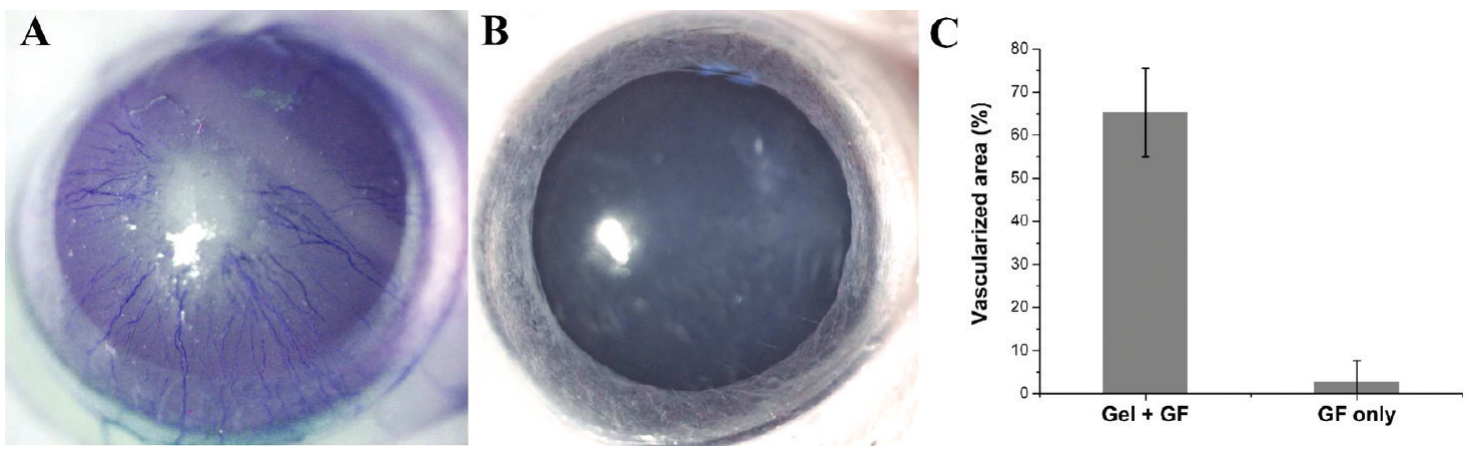

Figure 11. Evaluation of in vivo bioactivity by corneal angiogenesis assay. (A) Injection of 1 wt \% Heparin-mimetic PA gel with 10 ng of VEGF and bFGF-induced vascularization in cornea. (B) Application of growth factor solution (10 ng of VEGF and bFGF) in physiological saline (without PA gel) did not induce vascularization. (C) Ratio of vascularized area to total area was calculated for both groups $(n=3$ for each group). Heparin-mimetic PA gel with growth factor ( Gel + GF) was significantly higher than sole growth factor (GF) solution treatment as compared with Student's $t$ test $(p<0.001)$ $(n=3$ for both treatments).

was compared with the tissue culture plate. We observed that Heparin-mimetic PA scaffold enhanced the expression of genes for the aforementioned three stages of angiogenesis (VEGF at $6 \mathrm{~h}$, IA5 and IB3 at $24 \mathrm{~h}$, whereas Ang- 1 at $48 \mathrm{~h}$ ), and their mRNA levels peaked at expected time points. FGF-2 levels were lower than VEGF, indicating that angiogenic switch was mainly driven by VEGF. The Asp-PA scaffold upregulated genes involved in endothelial cell activation and migration (VEGF, IA5, IB3, and IA5), whereas it downregulated Ang-1 (Figure 9). This observation is consistent with in vitro tube formation results, where Asp-PA scaffold failed to form stable tube network, which is mainly maintained by Ang-1. Moreover, Heparin-mimetic PA nanofibers were more potent than Asp-PA regarding the expression of VEGF, IA5, IB3, and Ang-1, which indicates that Heparin-mimetic PA scaffold is actively triggering endothelial cells to enter into angiogenic route.

Because gene expression analysis in HUVECs revealed elevated expression of VEGF mRNA in endothelial cells cultured on Heparin-mimetic PA nanofibers and because capillary-like formations by endothelial cells can be triggered without any addition of exogenous VEGF by using these nanofibers, we sought whether VEGF secretion from HUVECs was also altered when cultured on Heparin-mimetic PA nanofibers by using ELISA (Figure 10). ELISA results revealed that time-dependent VEGF secretion from HUVECs on Heparin-mimetic PA matrices increased exponentially as a function of time. At the end of $48 \mathrm{~h}$, Heparinmimetic PA induced four times more VEGF secretion than bare tissue culture plate and nearly two times more than Asp-PA. These results suggest that besides elevated expression of VEGF, the induction of VEGF secretion is in effect. This might be due to autocrine signaling, where released VEGF molecules from cells are possibly entrapped and presented to the cells better with the Heparin-mimetic PA matrix, inducing the VEGF signaling pathways more robustly than the Asp-PA matrix and bare tissue culture plate.

The construction of robust vessels integrated into the circulatory system is crucial for functional tissue formation. To investigate in vivo efficacy of Heparin-mimetic PA nanofibers, a rat corneal micropocket neovascularization assay was used. Because the cornea is devoid of blood vessels, neo-vascularization in response to treatment condition can be easily detected. ${ }^{41}$ Our treatment groups included Heparin-mimetic PA gel with growth factors (VEGF/FGF-2 combination) and growth factor solution only.

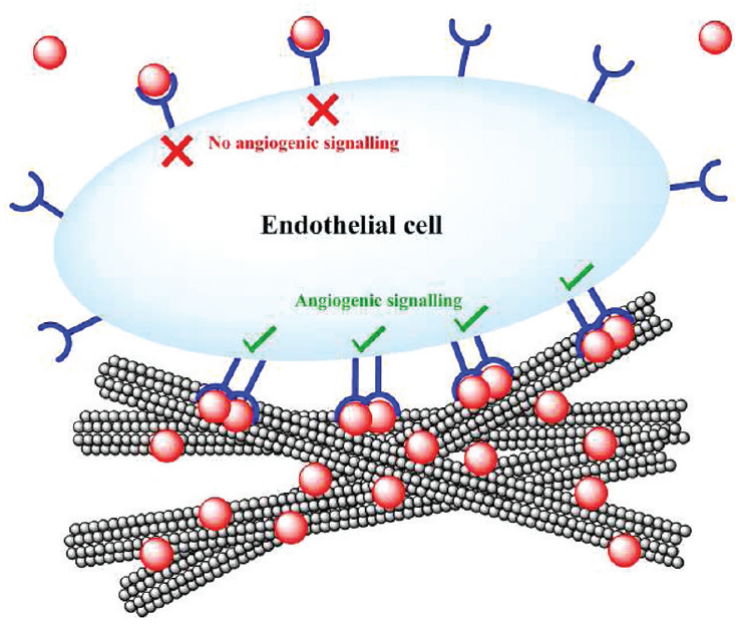

Figure 12. Suggested mechanism for induction of angiogenesis by bioactive Heparin-mimetic PA nanofibers. Heparin-mimetic PA nanofibers bind to growth factors (red balls) and present them to endothelial cells activating the angiogenic process.

Although the growth factor amount used was several times lower than the ones that were used in the literature, ${ }^{42}$ it was sufficient to induce neo-vascularization when used in combination with Heparin-mimetic PA gel. Moreover, vascularization after growth factor treatment without PA gel was significantly lower than that induced by growth factors in combination with Heparin-mimetic PA gel (Figure 11 and Figure S13 of the Supporting Information). In the corneal angiogenesis assay, the samples were introduced to the center of cornea, which is located far from the endothelial cells, and thus there are no detectable angiogenic growth factors in this area in healthy animals. Therefore, no significant vessel formation was observed in animals injected with Heparin-mimetic PA gel without growth factor (Figure S13 of the Supporting Information). This observation also shows that angiogenic activity observed in Figure 11a is not caused by inflammatory response against PA nanofibers but is because of slow release of growth factors from Heparin-mimetic PA gels. Moreover, Indian ink, which was used for perfusing the animals, entered and stayed in the newly formed capillaries, confirming that new vessels are robust and integrated to the circulatory system. 


\section{CONCLUSIONS}

In this study, the heparin need for growth factor activity was eliminated by using heparin-mimetic peptide nanofibers decorated with bioactive chemical groups (sulfonate, carboxylic acid, and hydroxyl). Various functional groups inspired by heparin were presented on the peptide scaffold besides the sulfonate group. The in vitro angiogenesis assays revealed that sulfonate group itself is not sufficient for an optimal angiogenic outcome. By using other biologically active chemical groups along with the sulfonate group, we were able to induce in vitro formation of capillary-like structures by mouse and human endothelial cells on bioactive peptide scaffold without further addition of growth factors and other angiogenic supplements (e.g., heparin). Endogenous angiogenic growth factors that bind to the bioactive PA nanofibers were sufficient for vessel formation. In addition, heparins induce more robust signaling when they are presented to the cells in a special conformation, ${ }^{11,43}$ and Heparin-mimetic PA nanofibers mimic this structure by presenting critical functional groups of heparin appropriately and induce more sustained growth factor signaling (Figure 12). Proper distribution of heparin-mimetic functional groups on the peptide nanofibers allows specific binding to endogenous growth factors released from cells and maintain their interaction with receptors on same cells. Potentially, Heparin-mimetic PA nanofibers bind to heparinbinding growth factors with a specific affinity, present them effectively to target receptors for the formation of active growth factor-receptor complex, and achieve sustained angiogenic signaling (Figure 12). Materials presented here provide new opportunities for angiogenesis and tissue regeneration by avoiding the use of heparin and exogenous growth factors. The synthetic scaffolds enriched with proper chemical functional groups shown here can induce the desired physiological response for tissue regeneration.

\section{ASSOCIATED CONTENT}

S Supporting Information. HPLC chromatograms, mass spectrometry analyses, zeta potential, AFM and SEM images of the PA molecules; in vitro angiogenic performances of HUVECs on different PA matrices; in vitro angiogenic performances of $\mathrm{H} 5 \mathrm{~V}$ cells on different PA matrices; electron micrographs of endothelial cells on tissue culture plate and Heparin-mimetic PA matrices; isothermal titration calorimetry (ITC) graphs for PA molecules titrated with VEGF; in vivo vascularization experiment for Heparin-mimetic PA only (without growth factors) and Heparin-mimetic PA with growth factors; loss tangents of PA gels $\left(G^{\prime \prime} / G^{\prime}\right)$; binding constants of VEGF with PAs derived by ITC experiment; primer sequences for the investigated genes taking role in angiogenesis process. This material is available free of charge via the Internet at http://pubs.acs.org.

\section{AUTHOR INFORMATION}

\section{Corresponding Author}

*E-mail: moguler@unam.bilkent.edu.tr (M.O.G.); atekinay@ unam.bilkent.edu.tr (A.B.T.). Tel: +90 3122903552 (M.O. G.); +90 3122903572 (A.B.T.). Fax: +90 3122664365 .

\section{ACKNOWLEDGMENT}

This work was supported by TUBITAK (110M355) and COMSTECH-TWAS grant. We would like to thank Z. E. Ulger,
Z. Erdogan, M. Guler, and Dr. H. Deniz for technical help. R. Mammadov is supported by TUBITAK BIDEB (2215) Ph.D. fellowship. M.O.G. acknowledges support from the Turkish Academy of Sciences Distinguished Young Scientist Award (TUBA GEBIP).

\section{REFERENCES}

(1) Lutolf, M. P.; Hubbell, J. A. Nat. Biotechnol. 2005, 23, 47-55.

(2) Kaully, T.; Kaufman-Francis, K.; Lesman, A.; Levenberg, S. Tissue Eng., Part B 2009, 15, 159-169.

(3) Phelps, E. A.; Garcia, A. J. Curr. Opin. Biotechnol. 2010, 21, 704-709.

(4) Benoit, D. S.; Schwartz, M. P.; Durney, A. R.; Anseth, K. S. Nat. Mater. 2008, 7, 816-823.

(5) Schlessinger, J.; Plotnikov, A. N.; Ibrahimi, O. A.; Eliseenkova, A. V.; Yeh, B. K.; Yayon, A.; Linhardt, R. J.; Mohammadi, M. Mol. Cell 2000, 6, 743-750.

(6) Fairbrother, W. J.; Champe, M. A.; Christinger, H. W.; Keyt, B. A.; Starovasnik, M. A. Structure 1998, 6, 637-648.

(7) Dougher, A. M.; Wasserstrom, H.; Torley, L.; Shridaran, L.; Westdock, P.; Hileman, R. E.; Fromm, J. R.; Anderberg, R.; Lyman, S.; Linhardt, R. J.; Kaplan, J.; Terman, B. I. Growth Factors 1997, 14, 257-268.

(8) Simons, M.; Rubanyi, G. M. Modern Concepts in Angiogenesis; Imperial College Press: London, 2007.

(9) Zhou, Z.; Wang, J.; Cao, R.; Morita, H.; Soininen, R.; Chan, K. M.; Liu, B.; Cao, Y.; Tryggvason, K. Cancer Res. 2004, 64, 4699-4702.

(10) Hynes, R. O. Science 2009, 326, 1216-1219.

(11) Figg, W. D.; Folkman, J. Angiogenesis: An Integrative Approach from Science to Medicine, 1st ed.; Springer: New York, 2008.

(12) Dvir, T.; Timko, B. P.; Kohane, D. S.; Langer, R. Nat. Nanotechnol. 2011, 6, 13-22.

(13) Rajangam, K.; Behanna, H. A.; Hui, M. J.; Han, X.; Hulvat, J. F.; Lomasney, J. W.; Stupp, S. I. Nano Lett. 2006, 6, 2086-2090.

(14) Rajangam, K.; Arnold, M. S.; Rocco, M. A.; Stupp, S. I. Biomaterials 2008, 29, 3298-3305.

(15) Guerrini, M.; Beccati, D.; Shriver, Z.; Naggi, A.; Viswanathan, K.; Bisio, A.; Capila, I.; Lansing, J. C.; Guglieri, S.; Fraser, B.; Al-Hakim, A.; Gunay, N. S.; Zhang, Z. Q.; Robinson, L.; Buhse, L.; Nasr, M.; Woodcock, J.; Langer, R.; Venkataraman, G.; Linhardt, R. J.; Casu, B.; Torri, G.; Sasisekharan, R. Nat. Biotechnol. 2008, 26, 669-675.

(16) Chow, L. W.; Bitton, R.; Webber, M. J.; Carvajal, D.; Shull, K. R.; Sharma, A. K.; Stupp, S. I. Biomaterials 2011, 32, 1574-1582.

(17) Chow, L. W.; Wang, L. J.; Kaufman, D. B.; Stupp, S. I. Biomaterials 2010, 31, 6154-6161.

(18) Kim, S. H.; Kiick, K. L. Peptides 2007, 28, 2125-2136.

(19) Freeman, I.; Kedem, A.; Cohen, S. Biomaterials 2008, 29, 3260-3268.

(20) Christman, K. L.; Vazquez-Dorbatt, V.; Schopf, E.; Kolodziej, C. M.; Li, R. C.; Broyer, R. M.; Chen, Y.; Maynard, H. D. J. Am. Chem. Soc. 2008, 130, 16585-16591.

(21) Maynard, H. D.; Hubbell, J. A. Acta Biomater. 2005, 1, 451-459.

(22) Dvir, T.; Timko, B. P.; Kohane, D. S.; Langer, R. Nat. Nanotechnol. 2010, 6, 13-22.

(23) Ruvinov, E.; Leor, J.; Cohen, S. Biomaterials 2010, 31, 4573-4582.

(24) Place, E. S.; Evans, N. D.; Stevens, M. M. Nat. Mater. 2009, $8,457-470$.

(25) Toksoz, S.; Mammadov, R.; Tekinay, A. B.; Guler, M. O. J. Colloid Interface Sci. 2011, 356, 131-137.

(26) Silva, G. A.; Czeisler, C.; Niece, K. L.; Beniash, E.; Harrington, D. A.; Kessler, J. A.; Stupp, S. I. Science 2004, 303, 1352-1355.

(27) Garlanda, C.; Parravicini, C.; Sironi, M.; De Rossi, M.; Wainstok de Calmanovici, R; Carozzi, F.; Bussolino, F.; Colotta, F.; Mantovani, A.; Vecchi, A. Proc. Natl. Acad. Sci. U.S.A. 1994, 91, 7291-7295.

(28) Baudin, B.; Bruneel, A.; Bosselut, N.; Vaubourdolle, M. Nat. Protoc. 2007, 2, 481-485. 
(29) Nakatsu, M. N.; Hughes, C. C. W. In Angiogenesis: In Vitro Systems; Elsevier Academic Press: San Diego, 2008; Vol. 443, p 65.

(30) Nishida, T.; Yasumoto, K.; Otori, T.; Desaki, J. Invest. Ophthalmol. Visual Sci. 1988, 29, 1887-1890.

(31) Stendahl, J. C.; Rao, M. S.; Guler, M. O.; Stupp, S. I. Adv. Funct. Mater. 2006, 16, 499-508.

(32) Anderson, J. M.; Andukuri, A.; Lim, D. J.; Jun, H. W. ACS Nano 2009, 3, 3447-3454.

(33) Folkman, J.; Haudenschild, C. Nature 1980, 288, 551-556.

(34) Arnaoutova, I.; Kleinman, H. K. Nat. Protoc. 2010, 5, 628-635.

(35) Aranda, E.; Owen, G. I. Biol. Res. 2009, 42, 377-389.

(36) Brown, A. Int. J. Mol. Sci. 2009, 10, 3457-3477.

(37) Brockhaus, M.; Ganz, P.; Huber, W.; Bohrmann, B.; Loetscher, H. R.; Seelig, J. J. Phys. Chem. B 2007, 111, 1238-1243.

(38) Ozawa, C. R.; Banfi, A.; Glazer, N. L.; Thurston, G.; Springer, M. L.; Kraft, P. E.; McDonald, D. M.; Blau, H. M. J. Clin. Invest. 2004, $113,516-527$.

(39) von Degenfeld, G.; Banfi, A.; Springer, M. L.; Wagner, R. A.; Jacobi, J.; Ozawa, C. R.; Merchant, M. J.; Cooke, J. P.; Blau, H. M. FASEB J. 2006, 20, 2657-2659.

(40) Claffey, K. P. Am. J. Pathol. 2002, 161, 7-11.

(41) Martin, S.; Murray, J. C. Angiogenesis Protocols, 2nd ed.; Humana: New York, 2009.

(42) Cao, R.; Brakenhielm, E.; Pawliuk, R.; Wariaro, D.; Post, M. J.; Wahlberg, E.; Leboulch, P.; Cao, Y. Nat. Med. 2003, 9, 604-613.

(43) Jakobsson, L.; Kreuger, J.; Holmborn, K.; Lundin, L.; Eriksson, I.; Kjellen, L.; Claesson-Welsh, L. Dev. Cell. 2006, 10, 625-634. 